\title{
Selective predation of tawny owls (Strix aluco) on yellow-necked mice (Apodemus flavicollis) and bank voles (Myodes glareolus)
}

\section{Peter Sunde ${ }^{1, *}$, Heidi Malene Forsom¹, Mohammad Nafi Solaiman Al-Sabi² \& Kristian Overskaug ${ }^{3}$}

1) Department of Bioscience, Aarhus University, Grenåvej 14, DK-8410 Rønde, Denmark ( ${ }^{*}$ corresponding author's e-mail: e-mail: psu@dmu.dk)

2) National Veterinary Institute, Division of Veterinary Diagnostics and Research, Technical University of Denmark, Bülowsvej 27, DK-1790 København V, Denmark

3) The Royal Norwegian Society of Sciences and Letters, Erling Skakkes gt. 47c, NO-7491 Trondheim, Norway

Received 12 Jan. 2012, final version received 6 July 2012, accepted 21 Aug. 2012

Sunde, P., Forsom, H. M., Al-Sabi, M. N. S. \& Overskaug, K. 2012: Selective predation of tawny owls (Strix aluco) on yellow-necked mice (Apodemus flavicollis) and bank voles (Myodes glareolus). - Ann. Zool. Fennici 49: 321-330.

Differential predation on certain classes of individuals within prey populations might make owls strong selective agents on their prey. We investigated selective predation of tawny owls (Strix aluco) on yellow-necked mice (Apodemus flavicollis, A.f.) and bank voles (Myodes glareolus, M.g.) for two years by comparing prey from owl nests with live-trapped individuals. The owls killed significantly more male M.g. (73\%) than females, but not more than expected from traps (57\%). For A.f., owls selected adults in favour of subadults, and for adults, individuals with longer femurs. Adult males of A.f. killed by owls had significantly heavier testes in relation their size than the trapped males. Prey selection did not correlate with size-adjusted body or spleen mass. Owl-killed A.f. had higher prevalences of the intestinal helminth Heligmosomoides sp. than trapped individuals, but hosted similar numbers of parasite species. Differential predation of tawny owls on yellow-necked mice and bank voles seems to reflect higher exposure to predator encounters of prime individuals rather than selection for substandard individuals.

\section{Introduction}

Predators are strong selective agents for their prey species, as is evident from the evolution of a wealth of anti-predator defenses (Caro 2005), and differential predation on certain age-classes may strongly affect the demography and population dynamics of prey populations (Meri et al. 2008, Pettorelli et al. 2011).
As predators often prey more intensively on certain groups of individuals within a population, knowledge of which classes of individuals that are more prone to predation ('selected') is of fundamental importance for understanding predatory interactions and individual strategies of prey. Hence, if predation rates are primarily dependent on the predator's ability to capture, subdue and kill the prey upon encounter, 
predators should, all other factors being equal, select for "substandard" individuals (the youngest, oldest, sickest or weakest) in the population (e.g Temple 1987, Alzaga et al. 2008). If predation rates on the other hand are primarily dependent on the encounter rates, prey selection might either reflect differential search images by the predator (predator's decision) or differential risk-taking through predator exposure in the prey (prey's decision of risk taking). In the latter case, differential exposure-caused predation rates may either be a "cost of reproduction" of high quality individuals (Magnhagen 1991, Norrdahl \& Korpimäki 1998) or the result of "risk-sensitive foraging" of food stressed individuals (e.g. Sunde et al. 2003, Creswell et al. 2010).

Previous studies of prey selection by avian predators on rodents indicate, that males are often preyed upon more intensively than females (Halle 1988, Christe et al. 2006, Taylor 2009) and subadults are preyed upon more intensively than mature individuals (Halle 1988, Dickman et al. 1991, Kittlein et al. 2001, Trejo \& Guthmann 2003, Meri et al. 2008), but in other cases adults are selected in favour of subadults (Karell et al. 2010). Within life history classes, avian predators have also been found to prey on certain size or weight classes at a higher rate than what would be expected from the estimated occurrence in the entire prey population (Derting \& Cranford 1989, Zalewski 1996, Taylor 2009, Karell et al. 2010). However, no consistent prey selection patterns appear to exist across different studies, which indicates that different predatorprey relationships and/or trade-offs for prey are in play in different small mammal populations exposed to avian predators.

The role of health status, immunocompetence, and parasitism and its influence on predation risk has also received attention, although there has also been some debate as to how to measure the immunocompetence of prey. For instance, the mass of the spleen, as an important part of the immune system, has been suggested to be positively correlated with immunocompetence in birds (Møller \& Erritsøe 2000), whereas other authors suggest that a larger spleen is merely the result of an immune response to an infection (Smith \& Hunt 2004). Indeed, several studies have found a positive correlation between the size of the spleen and infections with parasites or diseases (Vincent \& Ash 1978, Ali \& Behnke 1985, Garside et al. 1989, Watkins et al. 1991). Likewise, some studies have found individuals that succumb to predation to be more heavily infected with parasites than the rest of the population (Steen et al. 2002, Navarro et al. 2004).

As the different phases of the predatory process (searching, approaching, attacking and killing; Caro 2005) are often not observable in field conditions, comparisons of samples of individuals killed by predators with "reference" individuals, assumed to represent the live populations might provide useful first line information about which individuals of prey that faces the highest risks (e.g. Haukisalmi et al. 1994, Taylor 2009, Karell et al. 2010).

The aim of this study was to investigate prey selection of the tawny owl (Strix aluco) on its most important prey species, the yellow necked mouse (Apodemus flavicollis; A.f. hereafter) and the bank vole (Myodes glareolus; M.g.), in a situation where individuals of both species are assumed to invest heavily in reproductive effort (spring in years of abundant beech mast). We investigated the patterns of prey selection in relation to life history status (gender, age), body size, body condition (residual body weight), relative size of internal organs (spleen, heart, and liver), testicular weight (indicator of reproductive investment in males), and helminth parasite load. Given that owls should prey differentially on individuals with respect to any of these traits we should expect these traits to differ between owl-killed and reference individuals.

\section{Material and methods}

The study was conducted in Gribskov Forest (56 $\left.\mathrm{km}^{2}\right)$ in northern Zealand, Denmark $\left(55^{\circ} 59^{\prime} \mathrm{N}\right.$, $\left.12^{\circ} 19^{\prime} \mathrm{E}\right)$. The deciduous parts of the forest houses a well studied population of tawny owls mostly breeding in nest boxes in well-defined territories (Sunde \& Bølstad 2004). During two years $(2003,2007)$ with population peaks of $A . f$ and M.g., following major beech (Fagus sylvaticus) mast crops the preceding autumns, we collected prey from tawny owl nest boxes and live captured reference animals (25 March-10 May). 
In such post-mast years, radio-tagged tawny owls directed almost all their hunting effort to mature beech forest, and A.f. and M.g. comprised more than $90 \%$ of all prey items found in tawny owl nests and in regurgitated pellets (P. Sunde \& M. S. Bølstad unpubl. data). It is, therefore, reasonable to assume that tawny owls in both years concentrated most of their search efforts on these two prey species.

We collected A.f. and M.g. hoarded in the nest boxes and replaced them with substitute food (laboratory mice). In owl territories where we had collected prey items from the nest, we caught small rodents in live traps at the same time, to serve as a control group representing the actual rodent population in the forest. We used "Ugglan" traps, provided with bedding and food (raisins and sunflower seeds) and checked them twice a day. All A.f. and M.g. were euthanized in situ, labelled and placed separately in small plastic bags and frozen $\left(-18{ }^{\circ} \mathrm{C}\right)$ until further examinations that were carried out in the lab.

\section{Measurements}

Age was categorised as adult or subadult based on examination of sexual maturity. For males, the adult criterion was scrotal testes, and for females the adult criterion was presence of teats, foetuses, or signs of previous litters such as placental scars. For items from traps and intact items from nests, we measured the total body mass to the nearest $\mathrm{mg}$, and the mass of heart, liver, spleen and testicles. We used an average of three measurements (to the nearest $0.01 \mathrm{~mm}$ ) of the left femur bone as an estimate of the structural body size. Because of partial consumption (always from the head and downwards), weight measures (total weight and organ weights) could not be taken from all individuals, therefore analyses including these factors were based on slightly different number of observations (Table 1).

To study the prevalence of intestinal parasites, we examined smears (one smear per specimen) of the content of the colon under a light

Table 1. Partial selection coefficients from logistic regression models on the relative probability that a specimen of Apodemus flavicollis or Myodes glareolus would be preyed upon by tawny owls as opposed to being live-trapped as function of different predictor variables $(b=0$ indicates no selection, $b=1$ an increase in relative likelihood of being predated by 2.71 times $[\exp \{1\}]$ for each unit increase in the predictor value [covariates] or between levels [categorical variables]; e.g. $b=1.384$ for 'age' in A.f. indicates that adults are 4.0 times [exp\{1.384\}] more exposed to owl predation than subadults) when controlling for various other predictor variables, as indicated in 'controlling for'. Year and date are entered as nuisance parameters in all models as indicated with italics. Total sample sizes: $n_{t}$ $=$ numbers trapped, $n_{p}=$ numbers preyed upon (incomplete information from partially consumed specimens).

\begin{tabular}{|c|c|c|c|c|c|c|c|c|c|}
\hline \multirow[b]{2}{*}{ Variable } & \multirow[b]{2}{*}{ Controlling for } & \multicolumn{4}{|c|}{$\begin{array}{c}\text { A. flavicollis } \\
\left(n_{\mathrm{p}}=207, n_{\mathrm{t}}=76\right)\end{array}$} & \multicolumn{4}{|c|}{$\begin{array}{c}\text { M. glareolus } \\
\left(n_{\mathrm{p}}=39, n_{\mathrm{t}}=72\right)\end{array}$} \\
\hline & & $B$ & $\mathrm{SE}_{b}$ & df & $p$ & $B$ & $\mathrm{SE}_{b}$ & $d f$ & $p$ \\
\hline i: year (2004 vs. 2007) & $i i$ & 2.897 & 0.364 & 284 & $<0.0001$ & 0.783 & 0.593 & 107 & 0.190 \\
\hline ii: Julian date & $i$ & -0.045 & 0.017 & 284 & 0.009 & -0.138 & 0.025 & 107 & $<0.0001$ \\
\hline A: sex (male vs. female) & $i, i i, \mathrm{~B}$ & 0.062 & 0.355 & 273 & 0.86 & 1.069 & 0.623 & 102 & 0.09 \\
\hline B: age (adult vs. subadult) & $i, i i, \mathrm{~A}$ & 1.384 & 0.540 & 273 & 0.011 & 1.209 & 0.862 & 102 & 0.16 \\
\hline C: sex $\times$ age & $i, i i, \mathrm{~A}, \mathrm{~B}$ & -0.368 & 1.090 & 272 & 0.74 & 0.682 & 1.805 & 101 & 0.71 \\
\hline $\mathrm{D}$ : femur lenght (mm) & $i, i i, \mathrm{~A}, \mathrm{~B}, \mathrm{C}$ & 0.169 & 0.094 & 198 & 0.07 & 0.277 & 0.362 & 88 & 0.45 \\
\hline E: body weight (g) & $i, i i, \mathrm{~A}, \mathrm{~B}, \mathrm{C}, \mathrm{D}$ & 0.060 & 0.064 & 122 & 0.33 & -0.183 & 0.204 & 76 & 0.37 \\
\hline F: spleen weight $(\mathrm{g})$ & $i, i i, \mathrm{~A}, \mathrm{~B}, \mathrm{C}, \mathrm{D}$ & 1.550 & 2.513 & 138 & 0.54 & -2.324 & 6.502 & 79 & 0.72 \\
\hline G: liver weight $(\mathrm{g})$ & $i, i i, \mathrm{~A}, \mathrm{~B}, \mathrm{C}, \mathrm{D}$ & 0.450 & 0.889 & 126 & 0.62 & 0.140 & 2.101 & 73 & 0.95 \\
\hline $\mathrm{H}$ : heart weight $(\mathrm{g})$ & $i, i i, \mathrm{~A}, \mathrm{~B}, \mathrm{C}, \mathrm{D}$ & -4.651 & 4.978 & 133 & 0.35 & 3.580 & 9.976 & 77 & 0.72 \\
\hline $\mathrm{I}$ : testis weight of adult male $(\mathrm{g})$ & $i, i i, \mathrm{D}$ & 2.710 & 1.255 & 80 & 0.034 & 3.270 & 2.621 & 32 & 0.22 \\
\hline J: Heligmosomoides sp. & $i, i i, \mathrm{~A}, \mathrm{~B}, \mathrm{C}, \mathrm{D}$ & -1.312 & 0.591 & 111 & 0.023 & 1.157 & 1.108 & 71 & 0.30 \\
\hline K: Calodium hepaticum & $i, i i, \mathrm{~A}, \mathrm{~B}, \mathrm{C}, \mathrm{D}$ & 0.470 & 0.586 & 111 & 0.42 & 0.056 & 1.36 & 71 & 0.97 \\
\hline L: Number of parasite species & $i, i i, \mathrm{~A}, \mathrm{~B}, \mathrm{C}, \mathrm{D}$ & 0.485 & 0.356 & 111 & 0.18 & -0.644 & 0.760 & 71 & 0.40 \\
\hline
\end{tabular}


microscope and recorded the presence of the different parasite species based on the presence of their eggs following Thienpont et al. (1986).

\section{Statistical analyses}

We conducted the overall analyses for prey selection as a Resource Selection Function (RSF, Manly et al. 2002), considering specimens that were preyed upon as "used" resource units and trapped specimens as "available" resource units. We constructed generalised linear mixed models in SAS 9.2 (Littell et al. 2006) with a binary response variable (killed by owls as opposed to live-trapped) modelled with a logit link function and binomially distributed errors and restricted maximum likelihood estimation technique. A major advantage of using this modelling approach within the RSF framework is that partial or additive effects of different life history and phenotypic variables on relative predation risk can be expressed and tested alongside in terms of selection coefficients that indicate the change in relative likelihood for a resource unit (i.e. specimen) being selected as partial function of the change in value of predictor trait (Manly et al. 2002). Hence, a selection coefficient $(b)$ of 2.71 for testes mass measured in grams in A.f. (Table 1) indicates that the relative predation risk (odds ratio) of male A.f. doubles for every $0.256 \mathrm{~g}$ increase $(\ln 2 / b)$ in testis weight. Statistical models based on testing differences in the individual traits in question between the two types of fates yielded very similar results with regard to spotting statistical differences between owl-killed and trapped specimen, so even though caution has been raised against complex models with binomial error structures (Bolker et al. 2009) we feel safe about the statistical inferences from the analyses.

Explanatory factors were addressed in the statistical models in the following order: in order to control for confounding effects of previously entered variables (0) date and year, (1) sex and age (controlling for $\{0\})$, (2) skeletal size (controlling for $\{0,1\},(3)$ body and organ mass and parasite prevalences (controlling for $\{0,1,2\}$ ). For adult males we also analysed for variation in testes weight (indicator of high investment in mating behaviour), controlling for $\{0,2\}$. In all analyses, we also included date and sampling year as nuisance parameters.

Because it was practically possible to capture rodents in only nine out of the 32 owl territories wherein rodents were sampled in nest boxes, we did not include territory information as random effects in the final models, since this severely drained the analysis for statistical power owing to the unbalanced design. Various homogenous tests (divided on fate) did not indicate any measurable variation among territories (all $z$ values $\leq 1$ ), so we feel safe about excluding the effects of territory identity from the analyses.

For explanatory variables that appeared to correlate at least modestly $(p<0.10)$ with relative predation risk, we conducted post-hoc tests using the individual factor in question as response variable. This was done in order to further reveal and illustrate their relationship with owl predation risk.

\section{Results}

In total, we found 207 A.f. in owl nests and caught 76 in traps. For M.g., we collected 39 from nests and caught 72 in traps. If the two rodent species were equally likely to enter traps, tawny owls selected A.f. in favour of M.g. (logistic regression, adjusting for effect of sampling year and date: $b=1.58, \mathrm{SE}_{b}=0.449, p=0.0005$ ). In both species, the mean sampling dates were earlier for specimens from nest boxes compared to traps (Table 1).

\section{Correlations with sex and age}

Males comprised $55 \%$ of all A.f. and $73 \%$ of all $M . g$. killed by owls. In M.g., this male proportion was significantly higher than expected from parity (Fig. 1). In comparison, males comprised $51 \%$ of all live-captured A.f. and $57 \%$ of all M.g. (not significantly different: Table 1 and Fig. 1). In both species, prey from owl nests consisted almost entirely of sexually mature individuals (Fig. 2). Positive selection coefficient indicated that owls took more adult individuals than was caught in traps (Table 1 and Fig. 2), a difference that was statistically significant in A.f. 


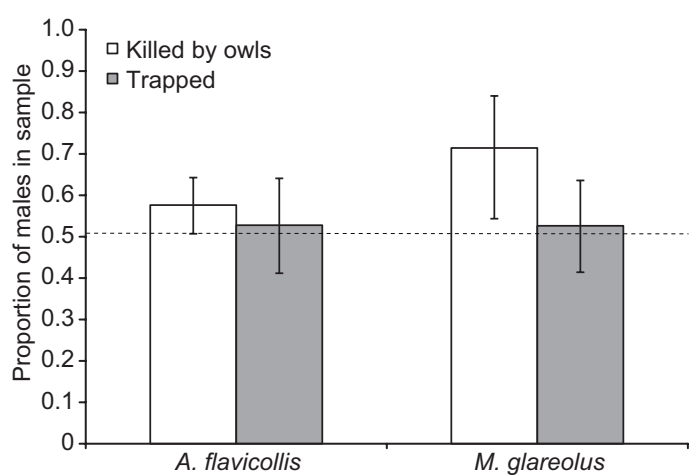

Fig. 1. Proportions of males amongst prey remains collected from tawny owl nests compared with livetrapped reference samples for Apodemus flavicollis and Myodes glareolus, March-April (least square mean estimates adjusted for year and sampling date. Error bars indicate $95 \% \mathrm{Cls}$ ). The reference dashed line indicates an even sex ratio.

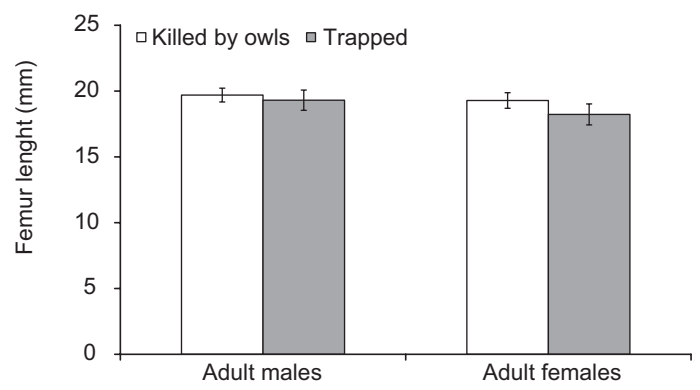

Fig. 3. Least square means and $95 \%$ confidence limits of femur length of adult Apodemus flavicollis caught by owls and live-trapped as reference divided on gender and adjusted for date and year (femur lengths modelled as function of fate [ $p=0.014]$, sex [ $p=0.038]$, sex $\times$ fate $[p=0.30])$, year $[p=0.78]$ and sampling date $[p=$ $0.87]$. If divided on sex, the differences in femur length between owl-killed and trapped mice is significant for females $(p=0.043)$ but not for males $(p=0.45)$.

\section{Correlations with phenotypic characters}

Specimens of A.f. killed by owls tended to be slightly larger than trapped individuals (Table 1), a difference that appeared to be most prominent among adult females (Fig. 3). When adjusting for skeletal size, owl-killed and live-trapped individuals did not differ with respect to body mass ("condition"), heart mass, spleen mass, nor liver mass (Table 1).

In both species, adult males killed by owls had heavier testes than those caught in traps, a

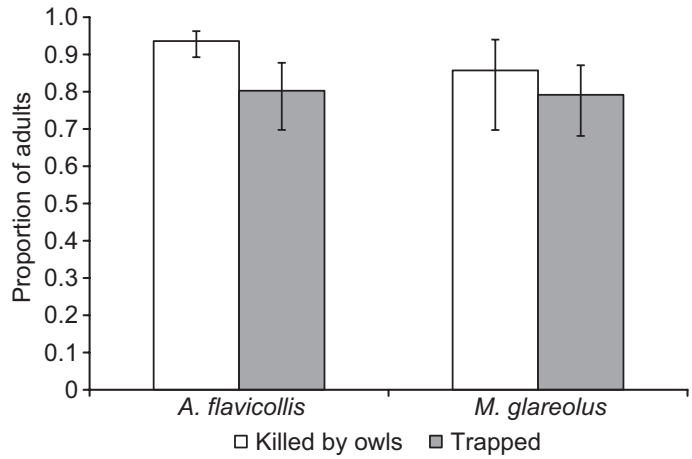

Fig. 2. Proportions of adults amongst prey remains collected from tawny owl nests compared with livetrapped reference samples for Apodemus flavicollis and Myodes glareolus, March-April (Least square mean estimates adjusted for year, sampling date and gender. Error bars indicate $95 \% \mathrm{Cls}$ ).

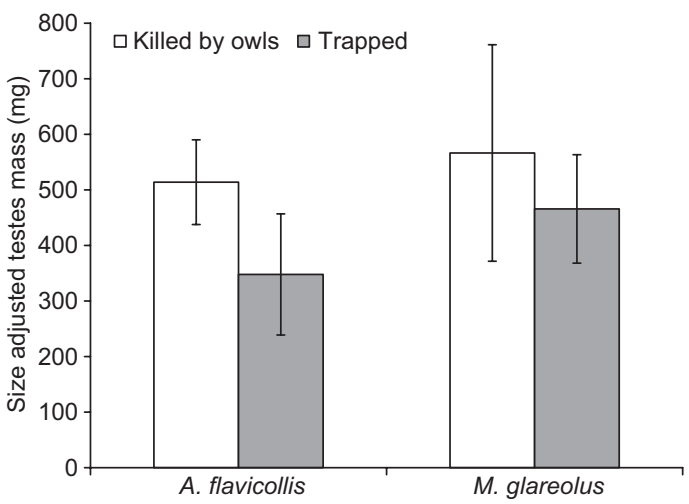

Fig. 4. Least square means with $95 \%$ confidence limits of size-adjusted testis mass of adult Apodemus flavicollis and Myodes glareolus related to whether they were collected from tawny owl nests or live-trapped as reference (from model where testis mass was modelled as function of year, date, femur length and fate [partial effects of fate: A.f.: $p=0.027$, M.g.: $p=0.39]$ ).

difference that was statistically significant in A.f. (Fig. 4 and Table 1).

\section{Prevalences of parasites}

In total, we identified the following parasitic nematodes in the digestive tracts (respective prevalences in 286 A.f and 110 M.g.): Calodium hepaticum: $52 \%$ and 16\%, Heligmosomoides sp.: $33 \%$ and $27 \%$, Nippostrongylus brasiliensis: $6 \%$ and 5\%, Trichuris muris: $16 \%$ and 0\%, Syphac- 


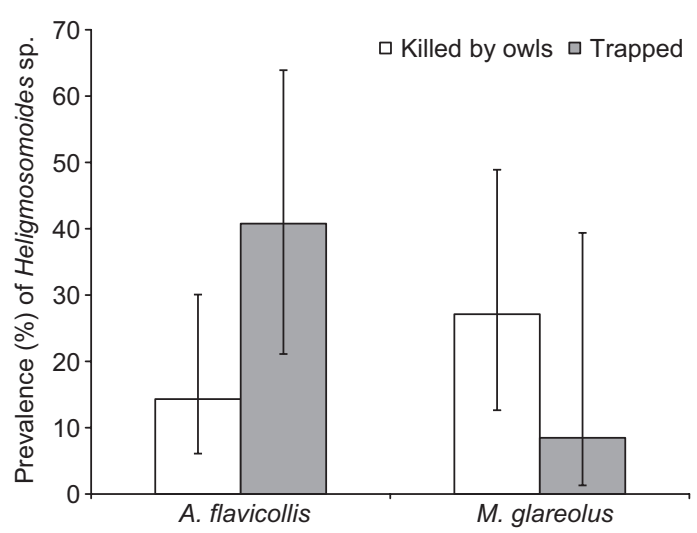

Fig. 5. Least square means with $95 \%$ confidence limits of proportion of Apodemus flavicollis and Myodes glareolus infected with the intestinal nematode Heligosomoides sp. related to whether they were collected from tawny owl nests or live-trapped as reference (from models where parasite prevalence were modelled as function of year, date, sex, age, femur length and fate [partial effects of fate: A.f: $p=0.018, M . g .: p=0.19]$ ).

ica muris: $1 \%$ and $0 \%$, other/unidentified species $11 \%$ and $4 \%$. The mean number of parasite species per individual was 1.2 for $A . f$. $(\mathrm{SD}=0.87)$, and 0.51 for M.g. $(\mathrm{SD}=0.69)$.

Heligmosomoides sp. was found significantly less often in A.f. killed by owls than in trapped individuals (Table 1 and Fig. 5). In M.g., we found a reverse, but not significant, trend (Table 1 and Fig. 5). The prevalence of $C$. hepaticum was not higher in rodents of either species taken by owls as compared with that in trapped animals, nor did we find any difference in the total number of parasites per specimen (Table 1). Parasite parameters did not correlate with spleen masses in any analyses (all $p$ values $>0.2$ ), but prevalences of $C$. hepaticum were higher in adult than in subadult A.f. (partial effect in logistic regression, $b=1.78, \mathrm{SE}_{b}=0.87, p=0.003$ ) and increased with femur length in M.g. ( $b=0.80$, $\left.\mathrm{SE}_{b}=0.36, p=0.03\right)$.

\section{Discussion}

Comparisons of specimens killed by tawny owls with live-trapped reference specimens, gave statistical evidence for tawny owls in A.f:: killing more adults than subadults; amongst the adults more larger individuals (particular in females); amongst adult males those with the heaviest testes; and finally fewer individuals with the intestinal parasite Heligmosomoides sp. In M.g., which comprised a smaller and statistically less powerful sample, males appeared to be taken more frequently than females and expected from an equal sex distribution. The fewer statistically significant selection parameters in M.g. compared to A.f. might be a mere result of lower statistical power due to smaller sample size. Hence, albeit statistically non-significant, selection coefficients for age, femur length and testis weight were larger in M.g. than in A.f. suggesting at least the same biological significance assuming that the difference was statistically factual. Even though only statistically significant results will be discussed in the following, we will therefore stress that more traits might be subject to differential predation hazards than identified here as statistically significant. The selection coefficients with SEs presented in this paper should therefore not necessarily be judged only on the basis of this isolated study, but might in the future contribute to a more comprehensive synthesis of individual traits associated with avian risks based on a meta-analysis of selection coefficient across a larger sample of field studies.

Finally, on an interspecific level, tawny owls appeared to prey more intensively on A.f. than on $M . g$. as compared with expectations from the live capture frequencies. This might indicate that $A . f$. were easier to locate and/or capture for tawny owls than M.g., and/or that the predator concentrated its searching effort on this (larger) of the two prey species.

\section{Reliability of data}

There is little reason to assume that specimens brought to nests should comprise a severely biased sample of the individuals caught from the same species, as most prey caught by owls during the sampling period were brought to the nests, and because no indications of differential consumption rates of specimens with different traits were apparent in the material. Studies of owl predation comparing remains in pellets with prey brought to the nest have found no differences between the two (Taylor 2009 and references therein). 
It is less certain whether trapped individuals were fully representative of the live population as those individuals that expose themselves to owl predation also might be more likely to enter traps. Hence, in both species, reproductive adults appear to be more willing to enter traps than subadults (Jensen 1975). Any such bias should underestimate the real prey selection of owls and thus make the analysis more conservative.

\section{Prey selection patterns of tawny owl on yellow-necked mice and bank voles}

In principle it is impossible to know from this study from which of the various stages of the hunting processes (searching, encountering, attacking, and killing), differential predation rates by tawny owls on their prey origin. However, given that tawny owls are ambush predators that hunt from perches a few metres above the ground, where they wait for prey to appear (Sunde et al. 2003), it is conceivable that differential predation rates are mainly a result of differential encounter and attack rates, which in turn will be a function of prey activity and exposure on the ground surface. In that case, relative differences in predation rates (selection coefficients) should reflect a similar variation in exposure to attack, e.g. risk sensitive foraging or mating behaviour (Magnhagen 1991).

When correcting for life-history traits, health and condition parameters did not correlate with relative predation risk. The present data indicate that tawny owls do not select individuals in poor condition or of low phenotypic quality such as individuals with small body size, poor body condition, low spleen mass or other organ measures that might be used as proxies for vitality and/or have been shown to correlate with predation risk in other studies (Koivunen et al. 1996b, Rohner \& Krebs 1996, Møller \& Erritzøe 2000, Møller \& Saino 2004, Corbin et al. 2008, Pettorelli et al. 2011). Instead, the traits that correlated with relative owl predation risk (more males, more adults, larger individuals and heavier testes in adult males) might all be associated with dominant and reproductively active individuals within a population.

Indications of males in general (M.g.) and those with the largest testes (A.f.) being rela- tively more prone to predation is in accordance with many other studies of the sex ratio in mammalian prey of owls (Donázar \& Ceballos 1989, Koivunen et al. 1996a, Christe et al. 2006, Taylor, 2009), and thus adds further evidence to the general notion that male reproductive strategies are costly in terms of exposure to avian ambush predation. Previously, testes mass has been linked to reproductive success in rodents (Schulte-Hostedde \& Millar 2004), and our results might point towards a trade-off in male A.f. between maximizing the copulation rate and life span through an increased owl predation risk. Owls often select subadults over adults (Dickman et al. 1991, Kittlein et al. 2001, Trejo \& Guthmann 2003, Meri et al. 2008), but may also select adults over subadults or large specimen over small ones (Derting \& Cranford 1989, Taylor 2009, Karell et al. 2010). The apparent selection for mature individuals (similar selection coefficients in both prey species, but only statistically significant difference in A.f.) by tawny owls in the present study might possibly be explained by the seasonal timing of the sampling period. In temperate, deciduous forests such as the one included in the study area, populations of M.g. and A.f. increase manifold from spring to autumn every year (Jędrzejewski et al. 1996, P. Sunde \& M. S. Bølstad unpubl. data). During the sampling period, sexually mature individuals of both genders should therefore invest heavily in reproductive activity in order to increase fitness and as a result also be more willing to run an increased predation risk compared to non-reproductive individuals (Magnhagen 1991, Norrdahl \& Korpimäki 1998). A prey selection study carried out in other seasons might therefore have resulted in different patterns. Hence, Taylor (2009) showed that barn owls (Tyto alba) selected strongly for male field voles (Microtus agrestis) in spring when males are known to be reproductively active and aggressive, whereas no selection was apparent in winter were all voles optimise survival.

For the case of reproductively active females, food searching in April is probably not only dangerous in terms of activity per se, but also related to the fact that beech seed densities are considerably higher in those microhabitats characterized by exposed soils which radio-tagged bank voles (and 
probably also other rodent species) strongly avoid in late autumn when beech seeds are still plentiful (Eskildsen 2010). Another possible factor is that immature individuals comprised less than $30 \%$ of the trapped individuals. Young individuals might not, therefore, have experienced the same territorial pressure that could expel them into predatorexposed microhabitats as might have been the case in other studies that have found selection for young individuals by owls. A prey selection study conducted in late summer and early autumn when the M.g. and A.f. populations were about to reach their seasonal peak could possibly reveal a different prey selection pattern.

For reasons that are not clear, the intestinal parasite Heligmosomoides sp. occurred less frequently in A.f. killed by owls than caught in traps. Heligmosomoides sp. has a direct lifecycle, releasing a large number of eggs into the environment in faeces of the host (Gregory et al. 1992). Infection by this parasite species occurs when the larvae are ingested by the host either from the substratum or during grooming (Gregory et al. 1992, Hernandez \& Sukhdeo 1995). A higher activity level in the host might, therefore, result in a higher rate of infections, as has been found to be the case with transmission rates in mice (Heitman et al. 2003). Heligmosomoides has also been associated with reduced individual performance in experimentally infected laboratory mice (Mus musculus) (Kavaliers \& Colwell 1995), which should also predict higher and not lower prevalence of this intestinal nematode in owl-killed A.f. if weakened individuals should be relatively more susceptible to predation.

Lack of overall correlations between the number of parasites and apparent predation risk, however, certainly does not support an unequivocal link between gut parasite infections and the risk of falling as prey for tawny owls. This conclusion is in line with a much similar study from Finland, where Ural owls (Strix uralensis) did not select field voles differentially in relation to infections with helminth parasite species in general (Haukisalmi et al. 1994).

As an overall conclusion, prey selection by tawny owls on yellow-necked mice and bank voles in spring following beech-seed masts, appeared to be related to differential exposure to owls of individuals pursuing different repro- ductive strategies. This assumption still remains to be tested on individually-marked focal individuals (e.g. Norrdahl \& Korpimäki 1998), but if true, tawny owls might not only limit population growth rates of these prey species in early spring directly by removing disproportionately more individuals of high reproductive value within the female segment of the population, but possibly also indirectly by forcing reproductively active individuals to reduce foraging activity and food intake during seasons of peak reproductive activity.

\section{Acknowledgements}

We are grateful to P. Christiansen and B. Jensen for field assistance and to P. Karell and I. Taylor for providing useful comments on a previous draft of this manuscript. Chris Topping kindly checked the language on the final version.

\section{References}

Ali, N. M. H. \& Behnke, J. M. 1985: Observations on the gross changes in the secondary lymphoid organs of mice infected with Nematospiroides dubius. - Journal of Helminthology 59: 167-174.

Alzaga, V., Vicente, J., Villanua, D., Avecedo, P., Casas, F. \& Gortazar, C. 2008: Body condition and parasite intensity correlates with escape capacity in Iberian hares (Lepus granatensis). - Behavioral Ecology and Sociobiology 62: 769-775.

Bolker, B. M., Brooks, M. E., Clark, C. J., Geange, S. W., Poulsen J. R., Stevens, M. H. H. \& White, J.-S. S. 2009: Generalized linear mixed models: a practical guide for ecology and evolution. - Trends in Ecology and Evolution 124: 127-135.

Caro, T. 2005: Antipredator defences in birds and mammals. - The University of Chicago Press, Chicago.

Corbin, E., Vicente, J., Martin-Hernando, M. P., Acevedo, P., Pérez-Rodríguez, L. \& Gortazar, C. 2008: Spleen mass as a measure of immune strength in mammals. Mammal Review 38: 108-115.

Christe, P., Keller, L. \& Roulin, A. 2006: The predation cost of being a male: Implications for sex-specific rates of agening. - Oikos 114: 381-384.

Cresswell, W., Lind, J. \& Quinn, J. L. 2010: Predator-hunting success and prey vulnerability: quantifying the spatial scale over which lethal and non-lethal effects of predation occur. - Journal of Animal Ecology 79: 556-562.

Derting, T. L. \& Cranford, J. A. 1989: Physical and behavioural correlates of prey vulnerability to barn owl (Tyto alba) predation. - The American Midland Naturalist 121: 11-20.

Dickman, C. R., Predavec, M. \& Lynam, A. J. 1991: Dif- 
ferential predation of size and sex classes of mice by the barn owl, Tyto alba. - Oikos 62: 67-76.

Donázar, J. \& Ceballos, O. 1989: Selective predation by eagle owls (Bubo bubo) on rabbits (Oryctolagus cuniculus): age and sex preferences. - Ornis Scandinavica 20: 117-122.

Eskildsen, A. 2010: Effects of resource abundance on habitat selection and spatial behavior of the bank vole (Myodes glareolus). - M.Sc. thesis, Univ. Copenhagen, Dept. of Biology.

Garside, P., Behnke, J. M. \& Rose, R. A. 1989: The immune response of male DSN hamsters to a primary infection with Ancylostoma ceylanicum. - Journal of Helminthology 63: 251-260.

Gregory, R. D., Montgomery, S. S. T. \& Montgomery, W. I. 1992: Population biology of Heligmosomoides polygyrus (Nematoda) in the wood mouse. - The Journal of Animal Ecology 61: 749-757.

Halle, S. 1988: Avian predation upon a mixed community of common voles (Microtus arvalis) and wood mice (Apodemus sylvaticus). - Oecologia 75: 451-455.

Haukisalmi, V., Henttonen, H. \& Pietiäinen, H. 1994: Helminth parasitism does not increase the vulnerability of field vole Microtus agrestis to predation by the Ural owl Strix uralensis. - Annales Zoologici Fennici 31: 263-269.

Heitman, T. L., Koski, K. G. \& Scott, M. E. 2003: Energy deficiency alters behaviours involved in transmission of Heligmosomoides polygyrus (Nematoda) in mice. Canadian Journal of Zoology 81: 1767-1773.

Hernandez, A. D. \& Sukhdeo, M. V. K. 1995: Host grooming and the transmission strategy of Heligmosomoides polygyrus. - The Journal of Parasitology 81: 865-869.

Jędrzejewski, W., Jędrzejewska, B., Szymura, A. \& Zub, K. 1996: Tawny owl (Strix aluco) predation in a pristine deciduous forest (Białowieża National Park, Poland). The Journal of Animal Ecology 65: 105-120.

Jensen, T. S. 1975: Trappability of various functional groups of the forest rodents Clethrionomys glareolus and Apodemus flavicollis, and its application in density estimations. - Oikos 26: 196-204.

Karell, P., Lehtosalo, N., Pietiäinen, H. \& Brommer, J. E. 2010: Ural owl predation on field voles and bank voles by size, sex, and reproductive state. - Annales Zoologici Fennici 47: 90-98.

Kavaliers, M. \& Colwell, D. D. 1995: Reduced spatial learning in mice infected with the nematode, Heligmosomoides polygyrus. - Parasitology 110: 591-597.

Kittlein, M. J., Vassallo, A. I. \& Busch, C. 2001: Differential predation upon sex and age classes of tucos-tucos (Ctenomys talarum, Rodentia: Octodontidae) by owls. - Mammalian Biology 66: 281-289.

Koivunen, V., Korpimäki, E. \& Hakkarainen, H. 1996a: Differential avian predation on sex and size classes of small mammals: doomed surplus or dominant individuals? Annales Zoologici Fennici 33: 293-301.

Koivunen, V., Korpimäki, E., Hakkarainen, H. \& Norrdahl, K. 1996b: Prey choice of Tengmalm's owl (Aegolius funereus funereus): preference for substandard individuals? - Canadian Journal of Zoology 74: 816-823.

Littell, R.C., Milliken, G. A., Stroup, W. V., Wolfinger, R. D.
\& Shabenberger, O. 2006: SAS ${ }^{\circledR}$ for mixed models, 2nd ed. - SAS Institute Inc., Cary, NC, USA.

Magnhagen, C. 1991: Predation risk as a cost of reproduction. - Trends in Ecology and Evolution 6: 183-186.

Manly, B. J. F., McDonald, L. L., Thomas, D. L., McDonald, T. L. \& Erickson, W. P. 2002: Resource selection by animals: statistical design and analysis of field studies (2nd ed.). - Kluwer Academic Publishers, London.

Meri, T., Halonen, M., Mappes, T. \& Suhonen, J. 2008: Younger bank voles are more vulnerable to avian predation. - Canadian Journal of Zoology 86: 1074-1078.

Møller, A. P. \& Erritzøe, J. 2000: Predation against birds with low immunocompetence - Oecologia 122: 500-504.

Møller, A. P. \& Saino, N. 2004: Immune response and survival. - Oikos 104: 299-304.

Navarro, C., de Lope, F., Marzal, A. \& Møller, A. P. 2004: Predation risk, host immune response, and parasitism. Behavioral Ecology 15: 629-635.

Norrdahl, K. \& Korpimäki, E. 1998: Does mobility or sex of voles affect risk of predation by mammalian predators? - Ecology 79: 226-232.

Pettorelli, N., Coulson, T., Durant, S. M. \& Gaillard, J. M. 2011: Predation, individual variability and vertebrate population dynamics. - Oecologia 167: 305-314.

Rohner, C. \& Krebs, C. J. 1996: Owl predation on snowshoe hares: consequences of antipredator behavior. - Oecologia 108: 303-310.

Schulte-Hostedde, A. I. \& Millar, J. S. 2004: Intraspecific variation of testis size and sperm length in the yellow-pine chipmunk (Tamias amoenus): implications for sperm competition and reproductive success. - Behavioral Ecology and Sociobiology 55: 272-277.

Smith, K. G. \& Hunt, J. L. 2004: On the use of spleen mass as a measure of avian immune system strength. - Oecologia 138: 28-31.

Steen, H., Taitt, M. \& Krebs, C. J. 2002: Risk of parasite-induced predation: an experimental field study on Townsend's vole (Microtus townsendii). - Canadian Journal of Zoology 80: 1286-1292.

Sunde, P. \& Bølstad, M. S. 2004: A telemetry study of the social organization of a tawny owl population. - Journal of Zoology, London 263: 65-76.

Sunde, P., Bølstad, M. S. \& Desfor, K. B. 2003: Diurnal exposure as a risk sensitive behaviour in tawny owls Strix aluco? - Journal of Avian Biology 34: 409-418.

Taylor, I. R. 2009: How owls select their prey: a study of barn owls (Tyto alba) and their small mammal prey. Ardea 97: 635-644.

Thienpont, D., Rochette, F. \& Vanparijs O. F. J. 1986: Diagnosing helminthiasis by coprological examination. Janssen Research Foundation, Beerse, Belgium.

Temple, S. A. 1987: Do predators always capture substandard individuals disproportionately from prey populations? - Ecology 68: 669-674.

Trejo, A. \& Guthmann, N. 2003: Owl selection on size and sex classes of rodents: Activity and microhabitat use of prey. - Journal of Mammalogy 84: 652-658.

Vincent, A. L. \& Ash, L. R. 1978: Splenomegaly in jirds (Meriones unguiculatus) infected with Brugia malayi (Nematoda: Filariodea) and related species. - American 
journal of tropical medicine and hygiene 27: 514-520.

Watkins, R. A., Moshier, S. E., O’Dell, W. D. \& Pinter, A. J. 1991: Splenomegaly and reticulocytosis caused by Babesia microti infections in natural populations of the montane vole Microtus montanus. - Journal of proto- zoology 38: 573-576.

Zalewski, A. 1996: Choice of age classes of bank voles Clethrionomys glareolus by pine marten Martes martes and tawny owls Strix aluco in Białowieża National Park. - Acta Oecologica 17: 233-244. 